\title{
Particle Diffusional Layer Thickness in a USP Dissolution Apparatus II: A Combined Function of Particle Size and Paddle Speed
}

\author{
JENNIFER J. SHENG, ${ }^{1}$ PAUL J. SIROIS, ${ }^{2}$ JENNIFER B. DRESSMAN, ${ }^{3}$ GORDON L. AMIDON ${ }^{1}$ \\ ${ }^{1}$ College of Pharmacy, University of Michigan, 428 Church Street, Ann Arbor, Michigan 48109-1065 \\ ${ }^{2}$ Lilly Research Laboratories, Eli Lilly and Company, Indianapolis, Indiana 46285 \\ ${ }^{3}$ Institute for Pharmaceutical Technology, Biocenter-Johann Wolfgang Goethe-University, Frankfurt 60439, \\ Germany
}

Received 2 August 2007; revised 25 December 2007; accepted 27 December 2007

Published online 3 March 2008 in Wiley InterScience (www.interscience.wiley.com). DOI 10.1002/jps.21345

\begin{abstract}
This work was to investigate the effects of particle size and paddle speed on the particle diffuisonal layer thickness $h_{\text {app }}$ in a USP dissolution apparatus II. After the determination of the powder dissolution rates of five size fractions of fenofibrate, including $<20,20-32,32-45,63-75$, and 90-106 $\mu \mathrm{m}$, the present work shows that the dependence of $h_{\text {app }}$ on particle size follows different functions in accordance with the paddle speed. At $50 \mathrm{rpm}$, the function of $h_{\text {app }}$ is best described by a linear plot of $h_{\text {app }}=9.91 \sqrt{d}-23.31\left(R^{2}=0.98\right)$ throughout the particle diameter, $d$, from 6.8 to $106 \mu \mathrm{m}$. In contrast, at $100 \mathrm{rpm}$ a transitional particle radius, $r$, of $23.7 \mu \mathrm{m}$ exists, under which linear relationship $h_{\text {app }}=1.59 r\left(R^{2}=0.98\right)$ occurs, but above which $h_{\text {app }}$ becomes a constant of $43.5 \mu \mathrm{m}$. Thus, $h_{\text {app }}$ changes not only with particle size, but also with the hydrodynamics under standard USP configurations, which has been overlooked in the past. Further, the effects of particle size and paddle speed on $h_{\text {app }}$ were combined using dimensionless analysis. Within certain fluid velocity/particle regime, linear correlation of $h_{\text {app }} / d$ with the square-root of Reynolds number $(d \varpi / v)^{1 / 2}$, that is, $h_{\text {app }} / d=1.5207-9.25 \times 10^{-4}(d \varpi / \nu)^{1 / 2}\left(R^{2}=0.9875\right)$, was observed. ( 2008 Wiley-Liss, Inc. and the American Pharmacists Association J Pharm Sci 97:4815-4829, 2008

Keywords: diffusion; diffusional layer thickness; dissolution; USP dissolution apparatus; in vitro models; particle size; hydrodynamics; fluid velocity; dimensionless number; gastrointestinal/mathematical models; bioequivalence; fenofibrate
\end{abstract}

\section{INTRODUCTION}

The Biopharmaceutics Classification System (BCS) categorizes drugs into four classes according to their solubility and permeability. ${ }^{1}$ The BCS II class of compounds exhibits high permeability and low solubility relative to the administered

Jennifer J. Sheng's present address is AstraZeneca Pharmaceuticals, Wilmington, DE 19850.

Correspondence to: Gordon L. Amidon (Telephone: 734-7642440; Fax: 734-763-6423; E-mail: glamidon@umich.edu)

Journal of Pharmaceutical Sciences, Vol. 97, 4815-4829 (2008) (c) 2008 Wiley-Liss, Inc. and the American Pharmacists Association dose. For a BCS II drug formulated into an immediate release (IR) dosage form, the combination of high drug permeability and adequate GI transit time will lead to a rate and extent of oral absorption that is controlled by the in vivo process of drug dissolution. ${ }^{1,2}$

Mechanistically, one of the fundamental issues in modeling and understanding dissolution is to determine the relationship between the diffusional layer thickness $\left(h_{\text {app }}\right)$ and particle size under a defined set of hydrodynamic conditions. In the past, the Noyes-Whitney equation $\mathrm{d} M /$ $\mathrm{d} t=-(D / h) A\left(C_{s}-C_{t}\right)$ has been widely used to 
describe drug particle dissolution, ${ }^{3}$ where $h$ is a thin static liquid layer at the solid surface under steady state conditions. For the past half century, the Noyes-Whitney equation has served as the theoretical basis for many classical dissolution models that assumed various relationships between the drug particle size and $h_{\text {app. For }}$ example, $h_{\text {app }}$ was assumed to be a constant by Hixson and Crowell, ${ }^{4}$ while Higuchi and Hiestand ${ }^{5-7}$ proposed that it was approximately equal to the radius of the particle, and Niebergall et al. ${ }^{8}$ determined it to be equal to the square root of the particle radius. All of these assumptions imply that the correlation between $h_{\text {app }}$ and particle size is applicable to all particle size ranges. In recent years, this correlation has been advanced by setting the existence of a transitional particle size, above and below which $h_{\text {app }}$ behaves differently depending on the magnitude of the drug particle radius. For example, based on modeling the dissolution of polydispersed powders, Hintz and Johnson ${ }^{9}$ proposed the concept of a transitional particle size. Specifically, $30 \mu \mathrm{m}$ was the critical particle radius. This model stipulates that $h$ is a constant of $30 \mu \mathrm{m}$ for particles with radii larger than $30 \mu \mathrm{m}$, while for particles less than $30 \mu \mathrm{m} h$ equals the particle radius. However, the transitional value of $30 \mu \mathrm{m}$ is based on a rotating disk hydrodynamic system, uses a compressed tablet, and powder size plays no role. This hypothesis seemed to have correlated reasonably well with their powder dissolution profiles and those in several subsequent studies. ${ }^{10,11}$ Nevertheless, direct evidence of the relationship between $h$ and various particle sizes $r$ in a USP dissolution apparatus II needs to be collected. Further, when such an assumption is extrapolated to a nonrotating disk system, well-defined hydrodynamic conditions merit careful considerations. Recently, Nystrom and colleagues used a Coulter Counter to directly measure particle size and concluded that a critical diameter of $15 \mu \mathrm{m}$ existed for griseofulvin and oxazepam, below which the $h_{\text {app }}$ decreased substantially with decreasing particle size. The effect of particle size on $h_{\text {app }}$ became less significant when particles diameters were above $15 \mathrm{\mu m}^{12}$ More recently, employing the same particle size measuring technique, Figueiredo et al. concluded that the critical particle size should be $22 \mu \mathrm{m}$ for ibuprofen, where the value of $h$ was linearly proportional to particle diameter $(k d)$ when the diameter was less than $22 \mu \mathrm{m}$ but was a constant $\left(k d_{\text {cri }}\right)$ when the particle diameter was above $22 \mu \mathrm{m} .^{13}$
In previously reported studies, even though the dependence of $h_{\text {app }}$ on particle size has been mathematically described, its dependence on the dissolution hydrodynamics has received very little consideration. Therefore, a complete examination of $h_{\text {app }}$ as a function of both particle size and pharmaceutically relevant hydrodynamic factors is theoretically and practically significant. In this article, we employed Eq. (1) to do so

$$
\frac{h_{\mathrm{app}}}{d}=a+b\left(\frac{d v^{0}}{v}\right)^{1 / 2}
$$

where $d$ is the drug particle diameter, $v^{0}$ is the linear velocity of fluid in $\mathrm{cm} / \mathrm{s}, v$ is the kinematic viscosity $\left(\mathrm{cm}^{2} / \mathrm{s}\right)$ of the fluid, $a$ and $b$ are parameters that can be estimated through experimental data. Mathematically, Eq. (1) is similar to Eq. (2),

$$
\frac{k d}{D}=2.0+0.6 \times\left(\frac{d v^{0}}{v}\right)^{1 / 2}\left(\frac{v}{D}\right)^{1 / 3}
$$

where $k$ is the mass transfer rate $(\mathrm{cm} / \mathrm{s})$, and $D$ is the diffusion coefficient of the drug molecule $\left(\mathrm{cm}^{2} /\right.$ s). As early as 1952 , Eq. (2) was theoretically derived and experimentally validated by Ranz and Marshall to describe the rate of evaporation of pure liquid drops and water drops containing dissolved and suspended solids, such as in spraydrying operations. ${ }^{14,15}$ In a subsequent article published in the same year, Ranz ${ }^{16}$ extrapolated his theory to mass transfer of single particles and packed beads. In 1954, Garner and his colleagues applied this theory to dissolution from a fixed solid sphere in fluid flow. ${ }^{17}$ Specifically, they found that the dissolution of benzoic acid in a stream of water was correlated with another equation of similar functional form to the Ranz-Marshall equation (Eq. 2), $k d / D=44+0.48\left(d v^{0} / v\right)^{1 / 2}(v / D)^{1 / 3}$. In 1960 , Bird $^{18}$ elaborated the Ranz-Marshall equation to describe simultaneous heat and mass transfer of a liquid or solid sphere under forced convection. In 1962, Harriott ${ }^{19}$ applied Eq. (2) for depicting mass transfer of benzoic acid, boric acid, zinc and lead sulfate particles suspended in agitated and baffled tanks. More recently, Fogler et al. employed Eq. (2) to study the dissolution of poly-dispersed particles. ${ }^{20}$ Drug powders dissolved in a USP dissolution apparatus II would encounter a similar hydrodynamic environment to that investigated in Harriott and Fogler's studies: that is, mass transfer from solid spheres under forced convection. 
In this article, fenofibrate was selected to serve as a model BCS II drug. Selection of USP II conditions is pharmaceutically relevant and of particular importance from a regulatory perspective. Moreover, five size fractions were utilized in the current study to further characterize and understand the impact of particle size on $h_{\text {app. The }}$ focus of this work is to: (1) determine the diffusion layer thickness $h_{\text {app }}$ for a BCS II model drug, fenofibrate, in a USP dissolution apparatus II; and (2) illustrate the dependence of $h_{\text {app }}$ on particle size and hydrodynamics using function form $h_{\text {app }} / d=a+b\left(d \nu^{0} / v\right)^{1 / 2}$.

\section{THEORETICAL SECTION}

\section{Calculation of Diffusional Layer Thickness $\boldsymbol{h}_{\text {app }}$}

The diffusion layer thickness $h_{\text {app }}$ of drug particles in a USP dissolution apparatus II can be calculated based on their dissolution rates. At dissolution time zero, the initial weight of a single drug particle is $M_{0}=(4 \pi / 3) \rho r_{0, v}^{3}$. At any time $t$ afterwards, the particle weight is $M_{t}=(4 \pi / 3) \rho r_{t, v}^{3}$, where $r_{0, v}$ and $r_{t, v}$ are the volume particle radius at time zero and $t$, respectively. $M_{0}$ and $M_{t}$ can be brought together by the mass balance of the drug particle, namely,

$$
M_{0}-M_{t}=\frac{\left(C_{t}\right) V}{N}
$$

where $N$ is the total number of particles, $C_{t}$ is the drug concentration at time $t$, and $V$ is the dissolution volume. In addition, the NoyesWhitney equation was originally derived in the slab coordinate. When it is applied to a spherical particle using spherical coordinate, it can be rewritten as $^{21,22}$

$$
-\frac{\mathrm{d} M}{\mathrm{~d} t}=D A\left(C_{s}-C_{t}\right)\left(\frac{1}{r}+\frac{1}{h_{\mathrm{app}}}\right)
$$

Eq. (4) can be simplified to the following:

$$
-\frac{\mathrm{d} r_{t}}{\mathrm{~d} t}=\frac{D\left(C_{s}-C_{t}\right)}{\rho}\left(\frac{1}{r_{t}}+\frac{1}{h_{\mathrm{app}}}\right)
$$

where $\rho$ is the density of drug particles, $C_{s}$ is the drug solubility in the dissolution medium, and $h_{\text {app }}$ is the apparent diffusion layer thickness. Thus, with known parameters including $C_{s}, C_{t}, \rho$, $V, D$, and $N$, the relationship between $r_{t}$ and $t$ can be established, the derivative of which is connected to $h_{\text {app }}$ through Eq. (5).
For a system that is approximately spherical, Eq. (4) is still valid. However, in the case of nonspherical shape, the particle mass $M$ should be related to the particle volume radius $r_{v}$, and the particle surface area $A$ should be related to the particle surface radius $r_{s}$. The volume radius $r_{v}$ can be measured directly by Coulter Counter method. The surface particle radius is calculated using equation $A=4 \pi r_{s}^{2}$, where the surface area $A$ is determined by BET methodology. Therefore, Eq. (4) can now be written as follows:

$$
\begin{aligned}
- & \frac{\rho 4 \pi r_{t, v}^{2} \mathrm{~d} r_{t, v}}{\mathrm{~d} t} \\
& =D 4 \pi r_{t, s}^{2}\left(C_{s}-C_{t}\right)\left(\frac{1}{r_{t, s}}+\frac{1}{h_{\mathrm{app}}}\right)
\end{aligned}
$$

Further, if the ratio of $r_{s} / r_{v}$ is assumed to be constant, then Eq. (6) can be simplified in the following:

$$
-\frac{\mathrm{d} r_{t, v}}{\mathrm{~d} t}=\left[\left(\frac{r_{s}}{r_{v}}\right) \frac{1}{h_{\mathrm{app}}}+\frac{1}{r_{t, v}}\right] \frac{D}{\rho}\left(\frac{r_{s}}{r_{v}}\right)\left(C_{s}-C_{t}\right)
$$

The ratio between the surface radius and volume radius, that is, $r_{s} / r_{v}$, is defined as the shape factor. This ratio is a fundamental property related to the particle dissolution rate in addition to drug solubility and diffusivity that are the essential factors dictating the diffusion and convection within the solid-liquid interface. The dissolution of an individual particle presumably proceeds in an isometric manner at the initial stage of the dissolution test. Therefore, the shape factor could be assumed as a constant in calculating the $h_{\text {app }}$ values. Assuming each size fraction is monodispersed, we employed Eqs. (3) and (7) to calculate $h_{\text {app. }}$. During early dissolution the change of particle radius and consequently that of $h_{\text {app }}$ are minimal. Therefore, generally the initial five dissolution data points were used for the determination of average $h_{\text {app }}$ values.

\section{Dependence of $h_{\text {app }}$ on Particle Size and Fluid Velocity}

The diffusion layer thickness $h_{\text {app }}$ for drug particles in a particular geometry is a function of drug properties including particle diameter $d$ and diffusivity $D$, and fluid properties of fluid velocity $v^{0}$ and kinematic viscosity $v^{23}$

$$
h_{\text {app }}=f\left(d, D ; v^{0}, v\right)
$$

Therefore we have $n=5$ variables for $h_{\text {app }}$ of drug particle dissolution in a USP vessel. These $n=5$ 
variables are built up from $k=2$ independent dimensions that are: length $L(\mathrm{~cm})$ and time $T(\mathrm{~s})$. According to the $\pi$-theorem, the variables $n=5$ can be reduced to three independent dimensionless numbers, which are defined as $h_{\text {app }} / d$, Reynolds number $R e=d v^{0} / v$ and Schmidt number $\underline{S c}^{\mathrm{Q} 2}=v / D$. Then, Eq. (8) can be expressed as

$$
\frac{h_{\mathrm{app}}}{d}=f(R e, S c)
$$

Most previous works, both theoretical and practical, ${ }^{14-17,19,20,24}$ suggested the form of:

$$
\frac{h_{\text {app }}}{d}=a+b \times(R e)^{1 / 2}(S c)^{1 / 3}
$$

In this study, the kinematic viscosity of dissolution medium $v$ and drug diffusivity of fenofibrate $D$ are constant, thus Eq. (1) arrives

$$
\frac{h_{\mathrm{app}}}{d}=a+b \times(R e)^{1 / 2}=a+b\left(\frac{d v^{0}}{v}\right)^{1 / 2}
$$

where $a$ and $b$ are constants and can be determined using regression analysis of the experimental data such as $h_{\text {app }}$ and $d$.

\section{EXPERIMENTAL}

\section{Materials and Preparation}

Fenofibrate ( $>99 \%$ purity), sodium lauryl sulfate and all other chemicals were of analytical grade and were purchased from Sigma Chemical Company (St. Louis, MO). Distilled, deionized and filtered water was prepared in house and used for all experiments. Fenofibrate "as received" from Sigma had a broad size distribution, with which four size fractions, that is, 20-32, 32-45, 63-75, and $90-106 \mu \mathrm{m}$ were obtained by sieving. In brief, the bulk material was initially dry sieved through the USA standard test sieves (Newark Wire Cloth Company, Clifton, NJ). Then, $300 \mathrm{mg}$ of the dry sieved fractions were well suspended into $60 \mathrm{~mL}$ of $0.9 \% \mathrm{NaCl}$ solution containing $0.05 \% \mathrm{SLS}$, and the suspensions were wet sieved through the same standard sieves. The wet sieved fractions on the sieve were rinsed with $0.9 \% \mathrm{NaCl}$ solution containing $0.05 \%$ SLS and subsequently with water, and then they were dried overnight in a vacuum oven at $30^{\circ} \mathrm{C}$. The $<20 \mu \mathrm{m}$ size fraction was achieved by jet-milling the bulk material as received from Sigma. About $100 \mathrm{~g}$ of fenofibrate bulk material was jet-milled through a lab scale size fluid energy grinder (Sturtevant Inc.,
Hanover, MA) that was operated using compressed nitrogen, with an approximate yield of 95\%. The milling air setting was 60-70 PSIG, and the feed air pressure was operated between 90 and 100 PSIG. The crystal form of the jet-milled fenofibrate was also characterized using powder X-ray diffraction (PXRD) and differential scanning calorimetry (DSC) to confirm the absence of amorphous material and process induced changes in crystal form. All the five fractions of particles were fully characterized with regards to their specific surface area, particle volume diameter, number diameter, and density. The USP pH 6.8 $50 \mathrm{mM}$ phosphate buffer without pancreatin was prepared following standard procedures. ${ }^{25}$ Piecewise regression analysis and parameter estimations were performed using Sigmaplot 10.0 (SPSS Inc., Chicago, IL). Two segment linear piecewise regression was applied to the particle radii $r$ and the corresponding $h_{\text {app }}$, at each paddle speed.

\section{Powder X-Ray Diffraction (PXRD)}

Powder diffraction patterns of jet-milled and "as received" fenofibrate were recorded with a Scintag X-ray diffractometer (Franklin, MA) using $\mathrm{Cu} \mathrm{K} \alpha$ radiation $(\lambda=1.54 \AA)$, tube voltage of $40 \mathrm{kV}$, and tube current of $20 \mathrm{~mA}$. The intensities were measured at $2 \theta$ values from $5^{\circ}$ to $40^{\circ}$ at a continuous scan rate of $5 \% \mathrm{~min}$.

\section{Differential Scanning Calorimetry (DSC)}

The thermal behavior of jet-milled and "as received" fenofibrate were studied using a TA Instruments 2920 modulated DSC (TA Instruments, New Castle, DE) with refrigerated cooling system (RCS) in standard mode. Approximately 5-10 mg samples were weighed into aluminum DSC pans, crimped, equilibrated to $-80^{\circ} \mathrm{C}$ and then heated up to $100^{\circ} \mathrm{C}$ at a rate of $5.0^{\circ} \mathrm{C} / \mathrm{min}$, with nitrogen purge at $110 \mathrm{~mL} / \mathrm{min}$.

\section{Particle Size Determination}

The mean volume particle size diameters for all size fractions were determined using the Coulter Counter (nonlaser light scattering) method. The jet-milled material was first suspended in the $0.9 \% \mathrm{NaCl}$ solution containing $0.25 \%$ SLS, saturated with fenofibrate. Then the suspension was quickly transferred into the $0.9 \% \mathrm{NaCl}$ solution 
containing $0.1 \%$ SLS and saturated with fenofibrate, which served as the suspending medium and testing electrolyte for all samples during particle size measurement. It should be emphasized that the diameter given by the Coulter is a volume equivalent diameter, namely, $d_{\nu}=(6 v / \pi)^{1 / 3}$, where $v$ is the particle volume directly measured by the Coulter.

\section{Specific Surface Area Measurement}

The specific surface area of fenofibrate powders was determined at liquid nitrogen temperature using BET methodology employing nitrogen as the adsorbate. The surface area was used to calculate the particle surface radius by equation $A=4 \pi r_{s}^{2}{ }^{26}$

\section{Solubility Measurement}

The aqueous solubility of fenofibrate was measured at $37^{\circ} \mathrm{C}$ in $0.25 \%$ SLS pH 6.8 phosphate buffer, instead of water. Since SLS has a CMC of $0.25 \%(\mathrm{w} / \mathrm{v})$ in water, it serves as a reasonable surrogate of the in vivo surfactant properties provided by bile salts and provides the necessary enhancement in solubility and dissolution rate for fenofibrate that is practically insoluble in water with a solubility of $<0.3 \mu \mathrm{g} / \mathrm{mL}$. Fenofibrate solubility was determined by suspending excess fenofibrate powder in $5 \mathrm{~mL}$ buffer in a screwcapped vial. The suspension was equilibrated by shaking in an orbital shaker water bath (LABLINE Instruments, Inc., Melrose Park, IL). At suitable time intervals, $1.0 \mathrm{~mL}$ of aliquots were drawn and filtered through $0.45-\mu \mathrm{m}$ membrane, and then diluted with an appropriate amount of phosphate buffer prior to the spectrophotometric assay at $\lambda=292 \mathrm{~nm}$ using a UV spectrophotometer (Beckman Coulter DU 650, Fullerton, CA). The equilibrium solubility of fenofibrate was established when the difference between three consecutive measurements is within $1 \%$, a process that may take up to 7 days.

\section{Dissolution Profiles in USP Dissolution Apparatus II}

The dissolution profiles of various size fractions of fenofibrate were measured in a USP dissolution apparatus II at $37^{\circ} \mathrm{C}$ using $\mathrm{pH} 6.8$ phosphate buffer containing $0.25 \%$ SLS. For the jet-milled fenobibrate, $50 \mathrm{mg}$ powder was weighed into a $1.0 \mathrm{~mL}$ of eppendorf tube, then $0.5 \mathrm{~mL}$ of the dissolution medium were added, and then the suspension was sonicated at low power for $5 \mathrm{~s}$. The well dispersed jet-milled suspension was then immediately transferred into the prepared dissolution vessel, and rinsed with the dissolution medium three times of $5 \mathrm{~mL}$ each. The four bigger size fractions of fenofibrate powders $(50 \mathrm{mg})$ were directly dropped into the $37^{\circ} \mathrm{C} 500 \mathrm{~mL}$ dissolution medium that was previously degassed. Dissolution experiments were conducted in triplicate at both 50 and $100 \mathrm{rpm}$ for each particle size. Aliquots were drawn at $0.33-1 \mathrm{~min}$ intervals, filtered through $0.45-\mu \mathrm{m}$ membrane and diluted if necessary prior to UV spectroscopic analysis at $\lambda=292 \mathrm{~nm}$ (BeckmanCoulter DU 650, Fullerton, CA).

\section{RESULTS}

\section{Characterization of Fenofibrate Particles}

As evident from the DSC traces of the jet-milled and "as received" fenofibrate (Fig. 1a and b), a negligible glass transition occurs around $-45^{\circ} \mathrm{C}$ with a very small enthalpy of $-0.0051 \mathrm{~W} / \mathrm{g}$, followed by the melting point around $79.5^{\circ} \mathrm{C}$ with an enthalpy of fusion of approximate $95 \mathrm{~J} / \mathrm{g}$. This DSC result indicates that no significant changes in crystal forms or amorphous content were introduced through the jet-milling process. These results are further confirmed by PXRD (Fig. 2) where the slightly decreased peak intensities are consistent with a reduction in particle size.

The volume particle size distribution of each size fraction is shown in Figure 3, and the surface area equivalent particle radius, shape factor and density for each size fraction are summarized in Table 1. Visual observation via SEM shows the irregular and multi-sided morphology of fenofibrate particles (Fig. 4), suggesting that fenofibrate particles would dissolve in a relatively isometric manner.

The diffusivity of fenofibrate was calculated as $7.4 \times 10^{-6} \mathrm{~cm}^{2} / \mathrm{s}$ using the ADMET Predictor ${ }^{\mathrm{TM}}$ 1.2.1 (Simulation Plus Co., Lancaster, CA), which used the Hayduk-Laurie formula $D=13.26 \times$ $10^{-5} / \eta_{\text {water }}^{1.4} V^{0.589} \cdot{ }^{27}$ This value is consistent with the literature reported experimental value of $7.15 \times 10^{-6} \mathrm{~cm}^{2} / \mathrm{s}$ using the rotating disk method. ${ }^{28}$

\section{Dissolution Profiles of Fenofibrate}

The solubility of fenofibrate was determined to be $150.4 \pm 1.4 \mu \mathrm{g} / \mathrm{mL}$ in $0.25 \%$ SLS $50 \mathrm{mM} \mathrm{pH} 6.8$ 

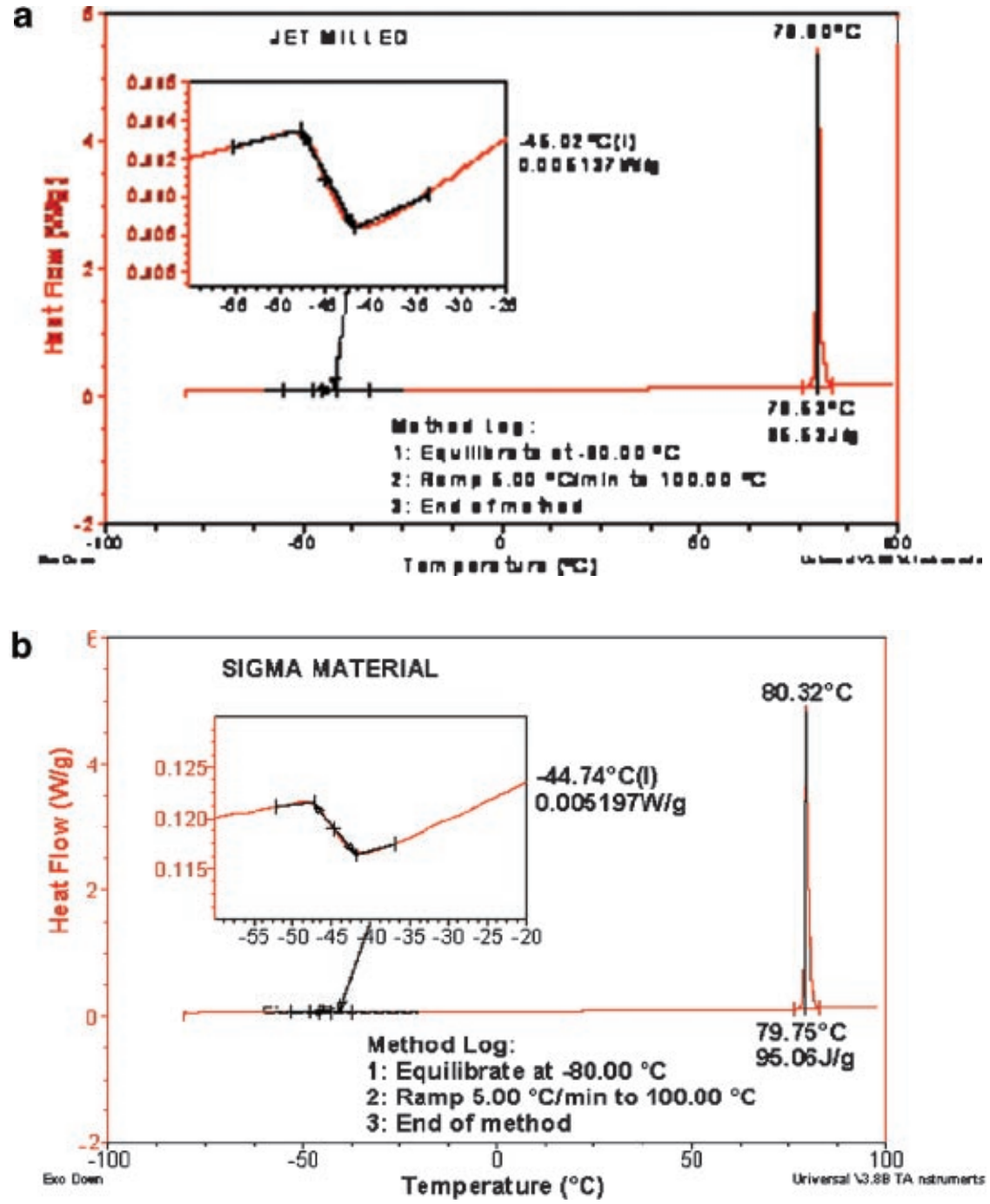

Figure 1. DSC thermogram of fenofibrate particles. a) Jet-milled fenofibrate particles of $<20 \mu \mathrm{m}$ diameter; b) Fenofibrate sample 'as received' from Sigma Chemical Company. Thermal scans obtained using 5-10 mg samples in crimped aluminum pans over a temperature range of $-80^{\circ} \mathrm{C}$ to $100^{\circ} \mathrm{C}$ at a scan rate of $5^{\circ} \mathrm{C} / \mathrm{min}$.

phosphate buffer. The dissolution profiles of fenofibrate particles at 50 and $100 \mathrm{rpm}$ are shown in Figure 5. Several elements can be drawn from these dissolution profiles. First, as expected, the dissolution rates increase with decreasing particle sizes in the following order: jet-milled material $(<20 \mu \mathrm{m})>20-32>32-45>63-75>90-106 \mu \mathrm{m}$ size fractions. This observation is consistent with the larger surface area per unit weight of the smaller particles. Secondly, the dissolution rates of the jet-milled material are similar at the 50 and $100 \mathrm{rpm}$. Finally, the four larger size fractions of fenofibrate dissolve faster at a paddle speed of $100 \mathrm{rpm}$ than at $50 \mathrm{rpm}$, presumably due to the higher fluid velocities at $100 \mathrm{rpm}$ that lead to thinning of $h_{\text {app }}$ and subsequently more efficient mass transfer.

\section{Dependence of Diffusional Layer Thickness on Hydrodynamics and Particle Sizes}

The dependence of $h_{\text {app }}$ on particle size and hydrodynamics/fluid velocity were examined and illustrated in the two following ways. The first approach is bifunctional analysis demonstrating $h_{\text {app }}$ as a function of $r$ under different paddle speeds, as shown in Figure 6. This approach determined the transitional particle size through which the value of $h_{\text {app }}$ exhibits a 


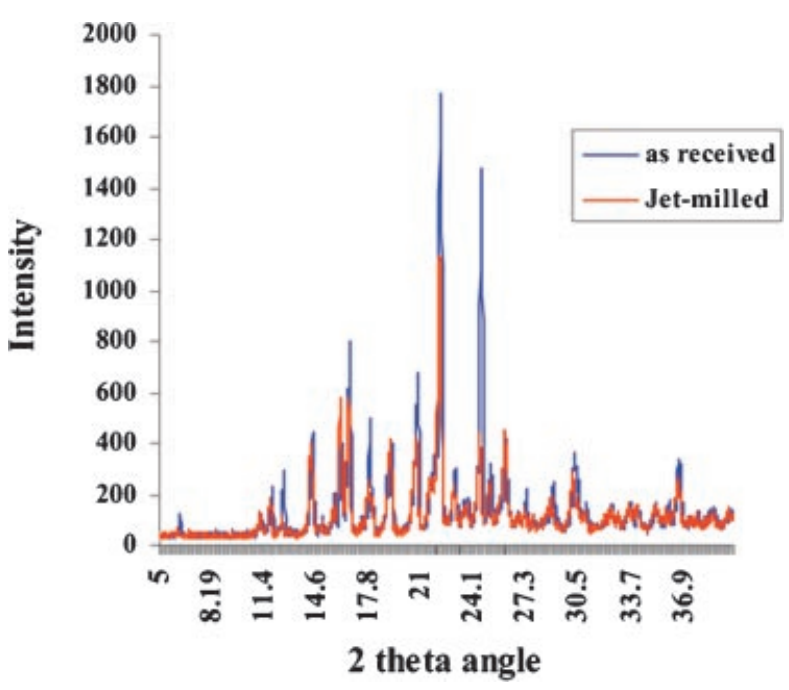

Figure 2. Overlay of powder X-ray diffraction patterns of jet-milled fenofibrate particles of $<20 \mu \mathrm{m}$ diameter and fenofibrate sample 'as received' from Sigma Chemical Company. Intensities were measured using $\mathrm{Cu} \mathrm{K} \alpha$ radiation at $2 \theta$ values from $5^{\circ}$ to $40^{\circ}$ at a scan rate of $5^{\circ} / \mathrm{min}$.

different correlation with particle radius. Determination of transitional particle size has been employed previously in the literature. ${ }^{9,12,13}$ The second approach is dimensionless analysis using Eq. (1), investigating the combined effects of particle sizes and paddle speeds on $h_{\text {app }}$.

Bifunctional analysis: The transitional particle size for fenofibrate in a USP dissolution apparatus II is fluid velocity dependant. Using piecewise regression, the transitional particle sizes are determined by the goodness of fitting using square root of overall correlation coefficient $\left(R^{2}\right)$, and the values are $37.7 \pm 5.4 \mu \mathrm{m}\left(R^{2}=0.9972\right)$ and $23.7 \pm$

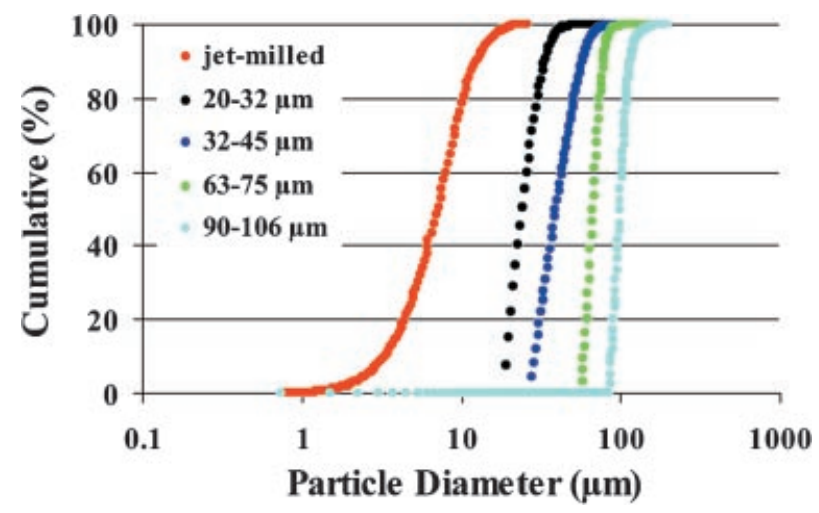

Figure 3. Semi-logarithmic plot of cumulative volume fraction of jet-milled and sieved fenofibrate particles as a function of particle diameter determined using a Coulter Counter.
$0.6 \mu \mathrm{m}\left(R^{2}=0.9998\right)$, under 50 and $100 \mathrm{rpm}$, respectively (Fig. 6). For drug particles smaller than the transitional sizes, the $h_{\text {app }}$ displays a linear relationship with the drug particle radius. The linear slopes vary with paddle speeds, and the values are $1.71\left(R^{2}=0.9872\right)$ and 1.59 $\left(R^{2}=0.9828\right)$, at 50 and $100 \mathrm{rpm}$, respectively. In comparison, for drug particles larger than the transitional sizes, at $100 \mathrm{rpm}$ a constant $h_{\text {app }}$ was observed with an approximate value of $43.5 \mu \mathrm{m}$ for any particles with radius larger than $23.7 \mu \mathrm{m}$; and at $50 \mathrm{rpm}$ the $h_{\text {app }}$ value continues to increase with particle size but at a slower rate. The bifunctional analysis also leads to the plot of $h_{\text {app }}$ versus $\sqrt{d}$, as shown in Figure 7. Evidently, at $50 \mathrm{rpm} h_{\text {app }}$ demonstrates a linear correlation with $\sqrt{d}$, that is, $h_{\text {app }}=9.91 \sqrt{d}-23.31, R^{2}=$ 0.9769 , throughout the tested particle size range 6.8-106 $\mu \mathrm{m}$ in this work. Whether this linear relationship applies to particles in near-micron or submicron range needs further research, partially due to the complex microfluid dynamics surrounding these very small particles. In comparison, at $100 \mathrm{rpm}$ the linear relationship transforms into plateau for larger particles. This dependence of $h_{\text {app }}$ on $\sqrt{d}$ was then further exploited in dimensional analysis.

Dimensionless analysis: According to Eq. (1) $h_{\mathrm{app}} / d=a+b\left(d v^{0} / v\right)^{1 / 2}$, the Re number $\left(d v^{0} / v\right)$ was calculated using drug particle diameter $d(\mathrm{~cm})$, linear fluid velocity $v^{0}(\mathrm{~cm} / \mathrm{s})$, and kinematic viscosity $v$ of dissolution medium $(0.758 \times$ $\left.10^{-2} \mathrm{~cm}^{2} / \mathrm{s}\right)$ at $37^{\circ} \mathrm{C} .^{29}$ The linear velocity of fluid/dissolution medium in an agitated USP vessel depends on the rotational speeds of paddle and the location in the vessel. In addition, the use of the linear velocity of the fluid is not convenient in practice, and the rotational speed of the paddle $\varpi$ is readily available and can be easily adjusted to the linear velocity through paddle diameter, that is, $\nu^{0}=\varpi \times$ paddle diameter. It therefore lends to the calculation of the Reynolds number using $\varpi$, that is, $d \varpi / v$. The relationship between $h_{\text {app }} / d$ and $d \varpi / v$ is proposed in Eq. (11):

$$
\frac{h_{\mathrm{app}}}{d}=a+b\left(\frac{d \varpi}{v}\right)^{1 / 2}
$$

where $R e$ is calculated based on the following: $d$ is the particle diameter in $\mu \mathrm{m}, \varpi$ is the rotational speed of paddle in rpm, $v$ is the kinematic viscosity of dissolution medium in $\mathrm{cm}^{2} / \mathrm{s}$, and the diameter of the paddle is well defined according to USP. Figure 8 demonstrates that the $h_{\text {app }}$ of suspended 
Table 1. Physical Characteristics of Various Size Fractions of Fenofibrate Powder

\begin{tabular}{|c|c|c|c|c|c|c|}
\hline $\begin{array}{l}\text { Particle Fractions } \\
(\mu \mathrm{m})\end{array}$ & $\begin{array}{c}\text { Number } \\
\text { Radius }^{a} \\
(\text { mean } \pm \mathrm{SD}) \\
(\mu \mathrm{m})\end{array}$ & $\begin{array}{c}\text { Surface } \\
\text { Radius }^{b} \\
(\text { mean } \pm \mathrm{SD}) \\
(\mu \mathrm{m})\end{array}$ & $\begin{array}{c}\text { Volume } \\
\text { Radius }^{c} \\
(\text { mean } \pm \mathrm{SD}) \\
(\mu \mathrm{m})\end{array}$ & $\begin{array}{c}\text { Specific } \\
\text { Surface Area } \\
(\text { mean } \pm \text { SD }) \\
\left(\mathrm{m}^{2} / \mathrm{g}\right)\end{array}$ & $\begin{array}{c}\text { Tapped } \\
\text { Density } \\
(\mathrm{g} / \mathrm{mL})\end{array}$ & $\begin{array}{l}\text { Shape } \\
\text { factor }^{d}\end{array}$ \\
\hline$<20 \mu \mathrm{m}$ (jet-milled) & $1.2 \pm 0.5$ & $2.7 \pm 0.5$ & $3.4 \pm 0.9$ & $1.575 \pm 0.058$ & $0.36 \pm 0.03$ & 0.79 \\
\hline $20-32 \mu \mathrm{m}$ & $13.8 \pm 6.2$ & $16.2 \pm 5.2$ & $16.1 \pm 0.6$ & $0.296 \pm 0.031$ & $0.64 \pm 0.02$ & 1.01 \\
\hline $32-45 \mu \mathrm{m}$ & $19.7 \pm 4.8$ & $28.4 \pm 3.0$ & $26.3 \pm 1.2$ & $0.181 \pm 0.002$ & $0.76 \pm 0.01$ & 1.09 \\
\hline $63-75 \mu \mathrm{m}$ & $34.4 \pm 4.4$ & $44.6 \pm 11.2$ & $37.1 \pm 1.0$ & $0.154 \pm 0.001$ & $0.76 \pm 0.02$ & 1.25 \\
\hline $90-106 \mu \mathrm{m}$ & $51.1 \pm 18.9$ & $56.3 \pm 14.5$ & $53.0 \pm 0.5$ & $0.083 \pm 0.006$ & $0.77 \pm 0.02$ & 1.06 \\
\hline
\end{tabular}

${ }^{a}$ Number radius was measured using scanning electronic microscopy (SEM).

${ }^{b}$ Surface radius was converted through the surface area that was measured by BET methodology.

${ }^{c}$ Volume radius was directly measured using Coulter Counter method.

${ }^{d}$ Shape factor was defined as the ratio of the surface equivalent radius to the volume equivalent radius, that is, $r_{s} / r_{v}$.

drug particles in the USP vessel can be successfully described with the semitheoretical equation (Eq. 11). Here, $h_{\text {app }} / d$ exhibits a two-regional dependence on particle $R e$, that is, $(d \varpi / v)^{1 / 2}$. One region is linear, where the particle $R e$ is $\geq 592$, and is described by $h_{\text {app }} / d=1.5207-9.25 \times$ $10^{-4}(d \varpi / v)^{1 / 2}$. Assuming the drug diffusivity is $7.15 \times 10^{-6} \mathrm{~cm}^{2} / \mathrm{s},{ }^{28}$ this regression corresponds to an $R^{2}=0.9875(p<0.0001)$, and estimates the values of $a=1.5207 \pm 0.0417$ and $b=-9.25 \times$ $10^{-4} \pm 4.66 \times 10^{-5}$. The other region describes the relation for particles with smaller Re number (either smaller particle size and/or slower paddle speeds), the relationship between $h_{\text {app }} / d$ and $R e$ may be more complex.

\section{DISCUSSION}

\section{Calculation of Diffusion Layer Thickness $\boldsymbol{h}_{\text {app }}$}

Due to its mathematical simplicity, a spherical shape is the best contour to select to experimen-

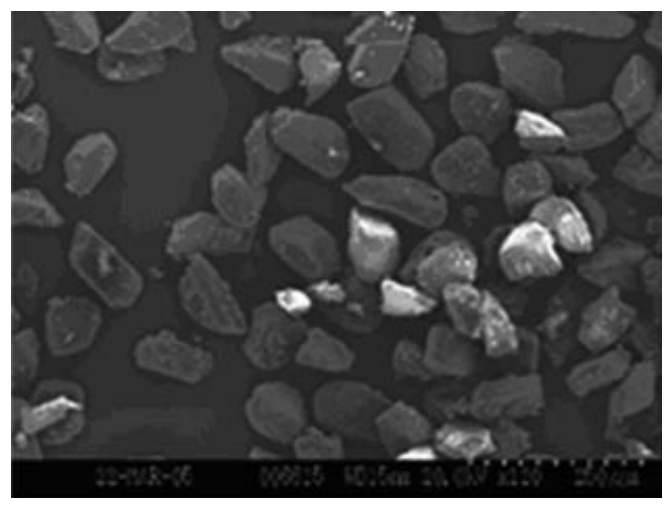

Figure 4. Typical Scanning Electron Micrograph of fenofibrate particles $(63-75 \mu \mathrm{m})$. tally determine the value of $h_{\text {app }}$, an approach that was elaborated by Wang and Flanagan. ${ }^{21,22}$ Numerous attempts to prepare spherical and crystalline fenofibrate particles for this study were unsuccessful because fenofibrate either formed amorphous spheres or crystalline needles following recrystallization processes as confirmed by polarized microscopy. Therefore, irregular shapes of fenofibrate particles were employed here with consideration given to their shape factor; that is, the ratio of particle surface radius to volume radius. Here, it is assumed that drug particles would dissolve in an approximately isotropic manner, implying that the shape factor would remain unchanged. This assumption has been used widely in the past when the shape factors were considered constant, in the initial stages of the dissolution testing. Even in the case of dissolving crystals with a high degree of

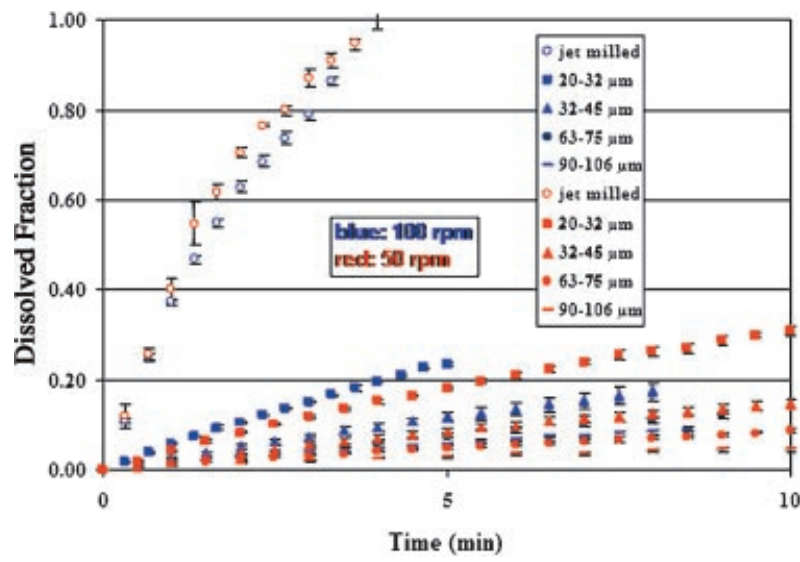

Figure 5. Dissolution profiles of jet-milled and sieved fenofibrate fractions in a USP Dissolution Apparatus II at $50 \mathrm{rpm}$ and $100 \mathrm{rpm}$. Dissolved fraction is shown as a function of time. Data expressed as mean $\pm \mathrm{SD}, \mathrm{n}=3$. 


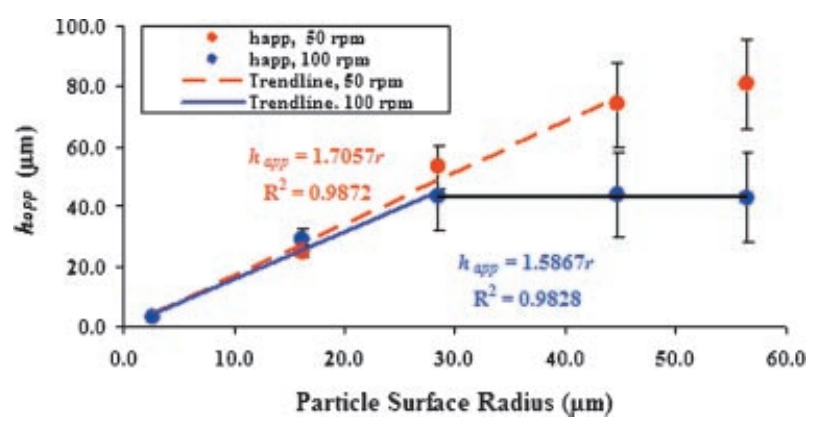

Figure 6. Bifunctional analysis of the dependence of particle boundary layer thickness, $h_{\text {app }}(\mu \mathrm{m})$, determined in a USP Dissolution Apparatus II at $50 \mathrm{rpm}$ and $100 \mathrm{rpm}$, on particle surface radius. Data expressed as mean $\pm \mathrm{SD}, \mathrm{n}=3$.

nonisometricity sharp edges such as needles and plates, the shape factor has been reported to change insignificantly until considerable dissolution occurs. ${ }^{30,31}$ In addition to the shape factor, the quantity of amorphous content, may also contribute to nonisometric dissolution. PXRD and DSC results confirmed the absence of detectable amorphous form for the jet-milled material.

The thickness of a hydrodynamic boundary layer is often defined as the distance from the surface of the solid to the point where the tangential velocity attains a value of $90 \%$ of the main stream. ${ }^{23}$ In general, this layer thickness is not easily evaluated from experimental work except under well-defined hydrodynamic conditions as in the case of the rotating-disk. ${ }^{23}$ In this work, the $h_{\text {app }}$ is calculated using Eq. (7) to

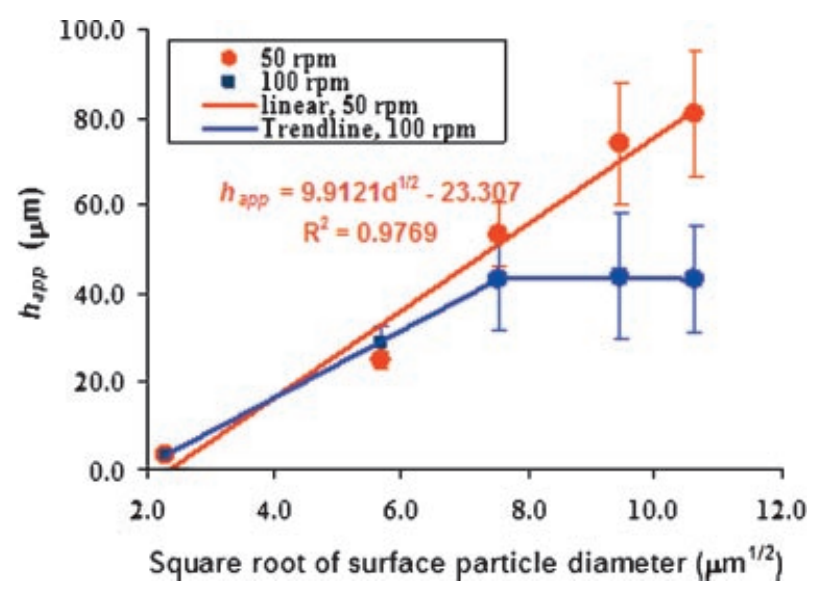

Figure 7. Plots of particle boundary layer thickness, $h_{\text {app }}(\mu \mathrm{m})$, determined in a USP Dissolution Apparatus II at $50 \mathrm{rpm}$ and $100 \mathrm{rpm}$, as a function of square root of particle surface radius. Data expressed as mean $\pm \mathrm{SD}, \mathrm{n}=3$.

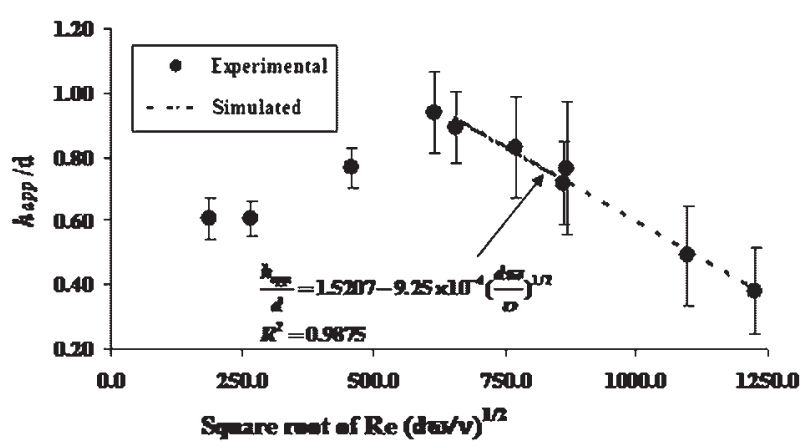

Figure 8. Dimensionless analysis of the dependence of diffusional layer thickness $\mathrm{h}_{\mathrm{app}}$ on particle sizes and hydrodynamics in a USP Dissolution Apparatus II. Data expressed as mean $\pm \mathrm{SD}, \mathrm{n}=3$.

describe the distance over which the diffusion process dominates the mass transfer. As such, it reveals the drug dissolution in terms of how resistance to mass transfer may occur in the solidliquid interface in a simple model. In addition, the diffusional thickness can often be used to predict changes in mass transfer caused by factors such as chemical reactions. ${ }^{32,33}$ It is important to note that the $h_{\text {app }}$ determined in a USP dissolution apparatus is an apparent averaged value from all particles. This averaged value is contributed from the following two factors. One factor is the specific hydrodynamic conditions, where the local environment of fluid dynamics surrounding each individual drug particle is not the same throughout the USP dissolution apparatus II vessel. ${ }^{34-38}$ The other factor is the monodispersion of the five size fractions is not perfect, even though they are all very narrowly distributed (Fig. 3).

\section{Dependence of $h_{\text {app }}$ on Hydrodynamics and Particle Sizes}

\section{Bifunctional Analysis with Transitional Particle Sizes}

Dissolution phenomena have been studied in a quantitative manner for more than a century, during which various relationships between $h_{\text {app }}$ and particle size have been proposed. ${ }^{5,8,9,12,13}$ Bifunctional analysis of fenofibrate dissolution data suggests that Higuchi-Hiestand's assumption $^{5,6}$ and Hintz-Johnson's hypothesis ${ }^{9}$ appear to be valid, whereas careful considerations should be given to the powder dissolution occurring under specific hydrodynamic conditions.

Higuchi-Hiestand assumed that $h_{\text {app }}$ was equal to or greater than the particle radius, and conducted their experiments with $2.2 \mathrm{mg}$ of micronized methylprednisolone $(\leq 25 \mu \mathrm{m})$ in $100 \mathrm{~mL}$ of water 
Table 2. Comparison of the Relationship between $h_{\text {app }}$ and $r$ in: Higuchi-Hiestand's Work, Hintz-Johnson's Work and the Current Work in a USP Dissolution Apparatus II

\begin{tabular}{lccc}
\hline & $\begin{array}{c}\text { Below } \\
C_{r}: h_{\text {app }} \text { as a } \\
\text { Function of } r\end{array}$ & $\begin{array}{c}\text { Critical } \\
\text { Particle Size: the } \\
\text { Value of } C_{r}(\mu \mathrm{m})\end{array}$ & $\begin{array}{c}\text { Above } \\
C_{r}: h_{\text {app }} \text { as a }\end{array}$ \\
\hline $\begin{array}{l}\text { Higuchi-Hiestand } \\
\text { Hintz-Johnson }\end{array}$ & $h_{\text {app }}$ is comparable to, or greater than the particle radius $r$ \\
$\begin{array}{l}\text { USP dissolution apparatus II, } r \\
\text { at 100 rpm }\end{array}$ & $h_{\text {app }}=1.59 r(r<23.7 \mu \mathrm{m})$ & 30 & Constant, $30 \mu \mathrm{m}$ \\
$\begin{array}{l}\text { USP dissolution apparatus II, } \\
\text { at 50 rpm }\end{array}$ & $h_{\text {app }}=1.71 r(r<37.7 \mu \mathrm{m})$ & 23.7 & Constant, approximate $43.5 \mu \mathrm{m}$ \\
\hline
\end{tabular}

in bottles that were rotated at $6 \mathrm{rpm}$ at $25^{\circ} \mathrm{C}^{5-7}$ In comparison with their work (Tab. 2), the current study experimentally demonstrates that in a USP dissolution apparatus II $h_{\text {app }}$ may be equal to or greater than particle radius $r$, only if the specific hydrodynamic conditions are provided. The first observation is based on the data that at paddle speed of $100 \mathrm{rpm}$, the particle radius $r$ of $44.6 \pm$ $0.4 \mu \mathrm{m}$ is not significantly different from the corresponding $h_{\text {app }}$ value of $43.5 \pm 11.2 \mu \mathrm{m}$. The second point was observed at both paddle speeds. For example, at $50 \mathrm{rpm} h_{\text {app }}$ equals to $1.71 r$, and the value of $h_{\text {app }}$ decreases to $1.59 r$ at a higher paddle speed of $100 \mathrm{rpm}$, both suggesting that $h_{\text {app }}$ could be greater than particle radius.

The description of $h_{\text {app }}$ as a function of particle size under both paddle speeds was compared with Hintz's work as well, as shown in Table 2. Both sets of data consistently demonstrate the existence of a transitional particle size $C_{r}$ in the $30 \mu \mathrm{m}$ size range, and a linear relationship between $h_{\text {app }}$ and $r$ when particle size is below $C_{r}$. When particle size is above $C_{r}$, a constant $h_{\text {app }}$ value, however, was observed at $100 \mathrm{rpm}$. Further, despite the similar observations, it is evident that distinct differences exist between the Hintz-Johnson's assumption and our work in the following specific aspects: (1) the value of $C_{r}$; (2) the linear slope value between the $h_{\text {app }}$ and $r$; and (3) the value of constant $h_{\text {app. }}$. These differences are attributed to the differences in hydrodynamic conditions under which the dissolution studies are conducted. In a rotating disk system, a planar constant surface area pertains rather than a powder dissolution of spherical geometry where more complex hydrodynamics pertains. For example, based on Levich's equation $h=1.61(D / v)^{1 / 3}(v / \varpi)^{1 / 2},{ }^{23}$ a diffusivity of fenofibrate as $7.15 \times 10^{-6} \mathrm{~cm}^{2} / \mathrm{s}$ and kinematic viscosity of the dissolution medium as $7.58 \times 10^{-3} \mathrm{~cm}^{2} / \mathrm{s}$ at $37^{\circ} \mathrm{C}$, for fenofibrate, a rotational speed of $21 \mathrm{rpm}$ would give a $h$ equals to $30 \mu \mathrm{m}$. Clearly, even though this assumption

Table 3. Particle Sizes and Re: Comparison of Fenofibrate Powder Dissolution in a USP Dissolution Apparatus II and Previous Studies Using the Function Form of Eq. (2)

\begin{tabular}{|c|c|c|}
\hline System & $\begin{array}{c}\text { Particle } \\
\text { Diameter } \\
\text { Range }(\mu \mathrm{m})\end{array}$ & Reynolds Numbers of Fluids \\
\hline USP dissolution apparatus $\mathrm{II}^{a}$ & $2-106$ & $0<R e<5.8 \times 10^{4}$ \\
\hline Mass transfer from single particles and packed beds ${ }^{4-6}$ & $600-1100$ & $1<\operatorname{Re}<7 \times 10^{5}$ \\
\hline Mass transfer ${ }^{b}$ from a fixed solid sphere in fluid flow ${ }^{7}$ & 1270 & $20<\operatorname{Re}<10^{3}$ \\
\hline Mass transfer ${ }^{c}$ of solid particles suspended in agitated tanks ${ }^{8}$ & $15-600$ & $325<\operatorname{Re}<1.08 \times 10^{5}$ \\
\hline Estimate $^{d}$ the $k$ value of polydisperse solid particles ${ }^{9}$ & Not defined & Not defined in the article \\
\hline Mass transfer of a single particle in creeping-flow ${ }^{10}$ & Not defined & $\begin{array}{c}\text { The correlation is very }{ }^{e} \text { good as of: } \\
1<R e<10^{3} \text {, reasonable as of: } \\
10^{3}<\operatorname{Re}<10^{4}\end{array}$ \\
\hline
\end{tabular}

\footnotetext{
${ }^{a}$ The unit for rotational speed $\varpi$ is rpm, for particle size $d$ is $\mathrm{cm}$.

${ }^{b}$ Overall mass transfer for the fixed sphere.

${ }^{c}$ The fluid velocity was estimated using slip velocity presented in Harriott's article.

$d_{k}$ is the mass transfer coefficient and equals to $D / h_{\text {app }}$.

${ }^{e}$ The experimental value is within $30 \%$ of the theoretical predicted values.
} 
seems to predict powder dissolution well in HintzJohnson study, the dissolution hydrodynamics in these two systems are very different.

\section{Dimensionless Analysis}

The key dissolution variables employed in Eq. (1), particle size and Reynolds number as an indicator of the fluid dynamics, were compared to the previous utilization of the Ranz-Marshall equation (Eq. 2). As shown in Table 3, the similarities and differences are discussed as follows. In Ranz's original work on mass transfer of single particles and packed beds, ${ }^{16}$ the theory was applied to particle sizes in the range of $0.06-1.1 \mathrm{~cm}$ and $R e$ number ranging from 2 to as high as $10^{5}$. In later studies, the particle size varied from 15 to $1270 \mu \mathrm{m}$, and the Re number ranged from 1 to $10^{5}$ (Tab. 3). Comparably, the $R e$ number under standard USP dissolution conditions such as 50 and $100 \mathrm{rpm}$ is within the Re range tested in the original Ranz theory ${ }^{14-16}$ and other work. $^{17,19,20,24,39}$ The $R e$ number in a USP dissolution apparatus II encompass a considerable range from a value of zero at the vessel wall to the highest value at the paddle tip. Using equation $R e=\varpi d_{\varpi}^{2} / v$, the maximum Re numbers can be determined as $2.9 \times 10^{4}$ and $5.8 \times 10^{4}$ at 50 and $100 \mathrm{rpm}$, respectively, ${ }^{35}$ where $\varpi$ is the rotational speed of the paddle, $d_{\varpi}$ is the diameter of the paddle, and $v$ is the kinematic viscosity of the fluid. Although the mean particle size in this work, $32-106 \mu \mathrm{m}$, is generally smaller than that utilized by Ranz's and others, our results have shown that the theoretical diffusion layer thickness $h_{\text {app }} / d=a+b\left(d \nu^{0} / v\right)^{1 / 2}$ could be extrapolated with remarkable accuracy to the particle size range beyond the Ranz's.

\section{Industrial Significance of $\boldsymbol{h}_{\text {app }}$}

Dependence of $h_{\mathrm{app}}$ on Paddle Speeds and Particle Size. Dimensionless analysis demonstrated a bipartite behavior of the dependence of $h_{\text {app }}$ on paddle speeds and particle size, which may be contributed by several factors. First, crystal defects and roughness on the particle surface represent a larger percentage of the crystal weight after milling, since the surface area to volume ratio is increased. These effects were observed to have a significant impact on dissolution rate for particles with diameters in the micron range. Second, at small particle sizes, turbulence in the form of microeddies begins to play a more important role in the hydrodynamics near to the dissolving surface, in other words a microenvironment different from the bulk hydrodynamics is created. ${ }^{40-42}$ It is also thought that the effective eddy diffusivity of drug molecule in the turbulent fluid may be very different from that in bulk fluid. ${ }^{43}$ Surface roughness, crystal defects and microeddies would lead to a faster dissolution rate than expected using surface area and the bulk fluid velocity. Further, jet-milling process generally produces small particles with radius of less than $10 \mu \mathrm{m}$, which is not perfectly monodispersed even though it is considered narrowly distributed compared with particles larger than $20 \mu \mathrm{m}$. Subsequently, any nonperfect monodisperse nature may contribute to the derivation of an accurate estimation of $h_{\text {app }}$. Employing the assumption of monodispersity for the jet-milled material may be an over-simplification, particularly if the dissolution investigation is primarily focused on particles less than $10 \mu \mathrm{m}$. However, even with the consideration of polydisperse nature (e.g., $1 \%$ particle with radius of $0.7,0.8$, and $1.05 \mu \mathrm{m}, 7 \%$ of $1.3 \mu \mathrm{m}, 6 \%$ of $6 \mu \mathrm{m}, 4 \%$ of $7 \mu \mathrm{m}$ and $1 \%$ of $9.5 \mu \mathrm{m}$ ), the $h_{\text {app }}$ value varies very little. The most plausible reason is that small particles contribute to negligible amount of overall weight fraction and the subsequent dissolution rate. Nevertheless, this region of small Re number merits further research.

Eq. (11), $h_{\text {app }} / d=a+b(d \varpi / v)^{1 / 2}$, was also applied to in vitro dissolution behavior of other drugs including digoxin and oxazepam independently reported by Nystrom et al. ${ }^{12,44}$ In their studies, dissolution rates were measured with two different particle sizes under three rotational speeds, that is, 350, 500, and $800 \mathrm{rpm}$. Dissolution rate data for digoxin fit the following the relationship:

$$
\begin{aligned}
\frac{h_{\mathrm{app}}}{d} & =22.17-0.012\left(\frac{d \varpi}{v}\right)^{1 / 2} ; \\
R_{\mathrm{sq}} & =0.9403(p=0.0052)
\end{aligned}
$$

For oxazepam, $h_{\text {app }}$ conforms to the following equation:

$$
\begin{aligned}
\frac{h_{\mathrm{app}}}{d} & =3.05-0.016\left(\frac{d \varpi}{v}\right)^{1 / 2} \\
R_{\mathrm{sq}} & =0.9472(p=0.0063)
\end{aligned}
$$

The successful fitting of digoxin and oxazepam dissolution data into the function form of Eq. (11) further supports the linear correlation between $h_{\text {app }} / d$ and $(d \varpi / v)^{1 / 2}$ and its use to estimate $h_{\text {app }}$ 
values for drug particles in the standard USP dissolution II apparatus, based on the measured particle size $d$ and the rotational paddle speed $\varpi$.

\section{$h_{\text {app }}$ for Poorly Soluble Drugs}

Recent estimates suggest that the percentage of BCS II drugs in the top US 200 oral IR products is greater than $25 \% .{ }^{45}$ Probably as a result of the widespread application of combinatorial chemistry and high-throughout screening activities during the drug discovery process, ${ }^{46,47}$ this percentage will probably increase. To ensure satisfactory oral absorption, particle size reduction has been widely used to increase the surface to volume ratio and thus improve the dissolution rate of poorly soluble drugs. The current work clearly reveals that the $h_{\text {app }}$ values generally decrease with decreasing particle size (Fig. 6). Therefore, an increase in the dissolution rate resulting from a particle size reduction process is attributed not only to an increase in the surface area to volume ratio, but also to a decrease in $h_{\text {app }}$, an important contribution that is rarely addressed in the literature.

In addition, since the layer thickness $h_{\text {app }}$ depends on the drug diffusivity $D$, the corresponding $h_{\text {app }}$ for two drug substances with different $D$ values would be expected to be different. However, it is likely that the $h_{\text {app }}$ would only change slightly because: (1) according to the Levich theory, ${ }^{23} h_{\text {app }}$ is only dependent to the one-third power on $D$, that is, $h=1.61(D / v)^{1 / 3}(v / \varpi)^{1 / 2}$ and (2) drug diffusivity of most small drug molecules is low and in the range of $10^{-6}-10^{-5} \mathrm{~cm}^{2} / \mathrm{s}$.

Furthermore, the results in this article suggest the following: (1) for drug particles with radius in the range of 3.4-23.7 $\mu \mathrm{m}, h_{\text {app }}$ is approximately 1.5fold of particle radius (Fig. 6), (2) under the paddle speed of $50 \mathrm{rpm}$, the diffusional $h_{\mathrm{app}}$ exhibits a linear relationship with the square root of particle diameter, across the studied particle size range (Fig. 7).

Finally, Figure 6 suggests that for small drug particles, $h_{\text {app }}$ is not significantly different under 50 and $100 \mathrm{rpm}$. The exact size range for the small particles, where $h_{\text {app }}$ is independent of paddle speeds in a USP dissolution apparatus II, is yet to be determined. In this work, the jet-milled fenofibrate with a mean $r_{v}$ of $3.4 \mu \mathrm{m}$, demonstrates that its $h_{\text {app }}$ is independent of fluid velocity. In the case of cilostazol, the size limit could be in the low micron range, that is, $13 \mu \mathrm{m}$. Cilostazol is a poorly soluble compound with a water solubility of $6.25 \mu \mathrm{g} / \mathrm{mL}$ at $37^{\circ} \mathrm{C}$. Three size fractions with mean particle sizes of $13,2.4$, and $0.22 \mu \mathrm{m}$ were prepared using techniques hammer-mill, jet-mill and spray-drying, respectively. In vitro powder dissolution profiles of $5 \mathrm{mg}$ of these cilostazol samples, in $900 \mathrm{~mL}$ of water, FaSSIF and FeSSIF at $37^{\circ} \mathrm{C}$ in USP apparatus II, were equivalent at the paddle speeds of 50 and $200 \mathrm{rpm} .{ }^{11}$ This result indicates that the $h_{\text {app }}$ is independent of paddle speeds when the cilostazol particles are smaller than $13 \mu \mathrm{m}$. Both results suggest that the hydrodynamic considerations are important for large particles, and very small particles in micron range are less influenced by hydrodynamics.

\section{Relevance to In Vivo Conditions}

The unique result, namely, $h_{\text {app }}$ is independent of fluid velocity for the very small particles, suggests that the highly variable GI fluid velocity varying with GI motility phases may not impact on the $h_{\text {app }}$ of low micron range particles in in vivo. The micronized powder of felodipine, with a median particle size of $8 \mu \mathrm{m}$, may be an example of such a drug. Felodipine is a poorly soluble, neutral and lipophilic drug, and its oral absorption that is indicated by AUC does not appear to be affected by the in vivo hydrodynamics in dog studies. ${ }^{48,49}$ The independence of $h_{\text {app }}$ on GI motility, for small particles such as jet-milled material, imply that the in vivo variability would be significantly reduced within subjects and between subjects. Therefore, reducing particle size not only improves the dissolution rate and absorption fraction for poorly soluble drugs, but also potentially minimizes the in vivo variability.

However, it should be emphasized here that establishing in vitro dissolution methodology reflecting in vivo scenario requires considerations in many aspects. For example, $\mathrm{pH}$ and surfactants are critical in selecting an appropriate dissolution medium. Additionally important factors include the fluid velocity and device geometry, which combine to determine the dissolution hydrodynamics. One disparity between dissolution testing and the in vivo situation is that the paddle speed remains unchanged during a given dissolution test. By contrast, the GI tract regularly transitions through migrating motility cycles and fasted or fed states. Hence, the GI fluid velocity varies considerably along various regions of small intestine,${ }^{50-53}$ which can lead to large inter- and intrasubject variations in in vivo $h_{\text {app }}$. To mimic the wide range of in vivo $h_{\mathrm{app}}$, it may be more 
appropriate to vary the in vitro hydrodynamic conditions during a test, for example, paddle speed (Type II tester), dip rate (Type III) and flow rates (Type IV). It is unrealistic to assume that use of a single USP dissolution setting such as $50 \mathrm{rpm}$ can reflect the complete hydrodynamics of a full GI motility cycle. However, a single paddle speed might be used to represent one certain GI motilityfluid flow and particle size combination.

Revision of the test apparatus design to better reflect the geometry of the intestinal tract and its flow patterns should be considered. One particularly important aspect to consider is the representation of oscillating flow, corresponding to the segmental mixing in the fed state, which is unique in its effects on in vivo $h_{\text {app. }}$. Applying dimensional principle, the in vivo $h_{\text {app }}$ is a function of: $h_{\text {app }} / d=f(R e, S c, S t)$, where Re and $S c$ are defined as previously, and $S t$ is the Strouhal number describing oscillatory fluid. St number is calculated as $S t=f l / \nu^{0}$, where $f$ is vortex shedding, $l$ is the characteristic length (hydraulic diameter), and $v^{0}$ is the linear velocity of GI fluid.

Potentially, a dimensionless analysis of the in vitro hydrodynamics and the in vivo GI motility using the rule of $h_{\text {app }} / d=f(R e, S c, S t)$ would be useful in improving accuracy of predicting in vivo dissolution and absorption of drug products, enhancing correlation between in vitro dissolution and in vivo response and developing in vitro bioequivalence methods.

\section{CONCLUSIONS}

The diffusional layer thickness $h_{\text {app }}$ was determined through fenofibrate powder dissolution testing in a USP apparatus II with various particle sizes and paddle speeds. The dependence of $h_{\text {app }}$ on drug particle size and dissolution hydrodynamics, reveals that at $100 \mathrm{rpm}$ the $h_{\text {app }}$ is approximate 1.5 -fold of the particle radius or a constant, which occurs below and above a transitional size of $23.7 \mu \mathrm{m}$, respectively. Further, the result at $50 \mathrm{rpm}$ suggests that a diffusional $h_{\text {app }}$ being linearly proportional to square root of particle diameter is an overall better functional form. Further, dimensionless analysis supports a linear correlation of $h_{\text {app }} / d$ with particle $R e$ within specific particle-hydrodynamic regime. However, the extrapolation of in vitro results to the in vivo situation requires further investigation due to the in vivo hydrodynamics varying with various GI motility phases.

\section{ACKNOWLEDGMENTS}

J.J.S. gratefully acknowledges the support of the American Foundation for Pharmaceutical Education and grant number GM07767 from NIGMS.

\section{REFERENCES}

1. Amidon GL, Lennernas H, Shah VP, Crison JR. 1995. A theoretical basis for a biopharmaceutic drug classification: The correlation of in vitro drug product dissolution and in vivo bioavailability. Pharm Res 12:413-420.

2. Lennernas H, Abrahamsson B. 2005. The use of biopharmaceutic classification of drugs in drug discovery and development: Current status and future extension. J Pharm Pharmacol 57:273-285.

3. Noyes AA, Whitney WR. 1897. J Am Chem Soc 19:930-934.

4. Martin AN, Bustamante P. 1993. Physical pharmacy: Physical chemical principles in the pharmaceutical sciences. 4th edition. Philadelphia: Lea \& Febiger. pp 333-334.

5. Higuchi WI, Hiestand EN. 1963. Dissolution rates of finely divided drug powders. I. Effect of a distribution of particle sizes in a diffusion-controlled process. J Pharm Sci 52:67-71.

6. Higuchi WI, Hiestand EN, Rowe EL. 1963. Dissolution rates of finely divided drug powders. 2. Micronized methylprednisolone. J Pharm Sci 52: 162-164.

7. Higuchi WI. 1967. Diffusional models useful in biopharmaceutics-Drug release process. J Pharm Sci 56:315-324.

8. Niebergall PJ, Milosovich G, Goyan JE. 1963. Dissolution rate studies. II. Dissolution of particles under conditions of rapid agitation. J Pharm Sci 52:236-241.

9. Hintz RJ, Johnson KC. 1989. The effect of particlesize distribution on dissolution rate and oral absorption. Int J Pharm 51:9-17.

10. Lu AT, Frisella ME, Johnson KC. 1993. Dissolution modeling: Factors affecting the dissolution rates of polydisperse powders. Pharm Res 10:13081314.

11. Jinno J, Kamada N, Miyake M, Yamada K, Mukai T, Odomi M, Toguchi H, Liversidge GG, Higaki K, Kimura T. 2006. Effect of particle size reduction on dissolution and oral absorption of a poorly watersoluble drug, cilostazol, in beagle dogs. J Contr Release 111:56-64.

12. Bistrat M, Anderberg EK, Barnett MI, Nystrom C. 1992. Physical aspects of drug release. 15. Investi- 
gation of diffusional transport in dissolution of suspended, sparingly soluble drugs. Int J Pharm 80:191-201.

13. deAlmeida LP, Simoes S, Brito P, Portugal A, Figueiredo M. 1997. Modeling dissolution of sparingly soluble multisized powders. J Pharm Sci 86:726732.

14. Ranz WE, Marshall WR. 1952. Evaporation from drops. 1. Chem Eng Pro 48:141-146.

15. Ranz WE, Marshall WR. 1952. Evaporation from drops. 2. Chem Eng Pro 48:173-180.

16. Ranz WE. 1952. Friction and transfer coefficients for single particles and packed beds. Chem Eng Pro 48:247-253.

17. Garner FH, Grafton RW. 1954. Mass transfer in fluid flow from a solid sphere. Proc R Soc Lond A 224:64-81.

18. Bird RB. 1960. Transport phenomena. New York: Wiley. pp $409 \& 647$.

19. Harriott P. 1962. Mass transfer to particles.1. Suspended in agitated tanks. AIChE J 8:93-101.

20. Leblanc SE, Fogler HS. 1987. Population balance modeling of the dissolution of polydisperse solidsRate limiting regimes. AIChE J 33:54-63.

21. Wang J, Flanagan DR. 1999. General solution for diffusion-controlled dissolution of spherical particles. 1. Theory. J Pharm Sci 88:731-738.

22. Wang J, Flanagan DR. 2002. General solution for diffusion-controlled dissolution of spherical particles. 2. Evaluation of experimental data. J Pharm Sci 91:534-542.

23. Levich VG. 1962. Physicochemical hydrodynamics. Englewood Cliffs, NJ: Prentice-Hall. pp 700.

24. Agarwal PK. 1988. Transport phenomena in multiparticle systems. 2. Particle-fluid heat and masstransfer. Chem Eng Sci 43:2501-2510.

25. USP. 2000. The United States Pharmacopeia USP 24,The National Formulary NF19. Rockville, Maryland: United States Pharmacopeial Convention, Inc. p 2236.

26. Allen T. 1997. Particle size measurement, 5th edition. London; New York: Chapman \& Hall. p 2 v.

27. Hayduk W, Laurie H. 1974. Prediction of diffusioncoefficients for nonelectrolytes in dilute aqueoussolutions. AIChE J 20:611-615.

28. Granero GE, Ramachandran C, Amidon GL. 2005. Dissolution and solubility behavior of fenofibrate in sodium lauryl sulfate solutions. Drug Dev Ind Pharm 31:917-922.

29. Dean JA, Lange NA. 1999. Lange's handbook of chemistry, 15th edition. New York: McGraw-Hill. p 5.134 .

30. Dali MV, Carstensen JT. 1996. Effect of change in shape factor of a single crystal on its dissolution behavior. Pharm Res 13:155-162.

31. Lai TYF, Carstensen JT. 1978. Effect of shape factor on cube root dissolution behavior. Int $\mathrm{J}$ Pharm 1:33-40.
32. Mooney KG, Mintun MA, Himmelstein KJ, Stella VJ. 1981. Dissolution kinetics of carboxylic acids I: Effect of $\mathrm{pH}$ under unbuffered conditions. J Pharm Sci 70:13-22.

33. Mooney KG, Mintun MA, Himmelstein KJ, Stella VJ. 1981. Dissolution kinetics of carboxylic acids II: Effect of buffers. J Pharm Sci 70:22-32.

34. Healy AM, McCarthy LG, Gallagher KM, Corrigan OI. 2002. Sensitivity of dissolution rate to location in the paddle dissolution apparatus. J Pharm Pharmacol 54:441-444.

35. Kukura J, Arratia PE, Szalai ES, Muzzio FJ. 2003. Engineering tools for understanding the hydrodynamics of dissolution tests. Drug Dev Ind Pharm 29:231-239.

36. McCarthy LG, Bradley G, Sexton JC, Corrigan OI, Healy AM. 2004. Computational fluid dynamics modeling of the paddle dissolution apparatus: Agitation rate, mixing patterns, and fluid velocities. AAPS Pharm Sci Tech 5:e31.

37. McCarthy LG, Kosiol C, Healy AM, Bradley G, Sexton JC, Corrigan OI. 2003. Simulating the hydrodynamic conditions in the United States Pharmacopeia paddle dissolution apparatus. AAPS Pharm Sci Tech 4:E22.

38. Baxter JL, Kukura J, Muzzio FJ. 2005. Shearinduced variability in the United States Pharmacopeia Apparatus 2: Modifications to the existing system. AAPS J 7:E857-E864.

39. Devotta I, Ambeskar VD, Mandhare AB, Mashelkar RA. 1994. The life time of a dissolving polymeric particle. Chem Eng Sci 49:645-654.

40. Brian PLT, Hales HB, Sherwood TK. 1969. Transport of heat and mass between liquids and spherical particles in an agitated tank. AIChE J 15:727732 .

41. Sherwood TK, Pigford RL, Wilke CR. 1975. Mass transfer. New York: McGraw-Hill. p ix, 677.

42. Diebold SM. 2000. Hydrodynamik und Lösungsgeschwindigkeit: Untersuchungen zum Einfluss der Hydrodynamik auf die Lösungsgeschwindigkeit schwer wasserlöslicher Arzneistoffe. Institute for Pharmaceutical Technology. Frankfurt: Johann Wolfgang Goethe University.

43. Bird RB, Stewart WE, Lightfoot EN. 2002. Transport phenomena, 2nd edition. New York: John Wiley. p xii, 895.

44. Bisrat M, Nystrom C. 1988. Physicochemical aspects of drug release. 8 . The relation between particle size and surface specific dissolution rate in agitated suspensions. Int J Pharm 47:223-231.

45. Takagi K, Ramachandran C, Bermejo M, Yamashita S, Yu LX, Amidon GL. 2006. A provisional biopharmaceutical classification of the top 200 oral drug products in the United States, Great Britain, Spain, and Japan. Mol Pharm 3:631-643.

46. Lipinski CA, Lombardo F, Dominy BW, Feeney PJ. 1997. Experimental and computational approaches 
to estimate solubility and permeability in drug discovery and development settings. Adv Drug Deliv Rev 23:3-25.

47. Lipinski CA. 2000. Drug-like properties and the causes of poor solubility and poor permeability. J Pharmacol Toxicol Methods 44:235-249.

48. Scholz A, Kostewicz E, Abrahamsson B, Dressman JB. 2003. Can the USP paddle method be used to represent in-vivo hydrodynamics? J Pharm Pharmacol 55:443-451.

49. Scholz A, Abrahamsson B, Diebold SM, Kostewicz E, Polentarutti BI, Ungell AL, Dressman JB. 2002. Influence of hydrodynamics and particle size on the absorption of felodipine in labradors. Pharm Res 19:42-46.
50. Meyer JH, Dressman J, Amidon G. 1985. Hydrodynamic aspects of gastrointestinal (GI) transit. Nippon Heikatsukin Gakkai Zasshi 21:99-100.

51. Meyer JH, Doty JE. 1988. GI transit and absorption of solid food: Multiple effects of guar. Am J Clin Nutr 48:267-273.

52. Oberle RL, Chen TS, Lloyd C, Barnett JL, Owyang C, Meyer J, Amidon GL. 1990. The influence of the interdigestive migrating myoelectric complex on the gastric emptying of liquids. Gastroenterology 99:1275-1282.

53. Sirois PJ, Amidon GL, Meyer JH, Doty J, Dressman JB. 1990. Gastric emptying of nondigestible solids in dogs: A hydrodynamic correlation. Am J Physiol 258:G65-G72. 